\title{
Situation Analysis on the Degree of Dependence on Loneliness and Social Network of Medicos
}

\author{
Ruixue Zhang, Tongyu Ma, Jieping Zhang, Xiaoyan Cao \\ School of Humanities and Management, Southwest Medical University, Luzhou 646000, China
}

\begin{abstract}
Purpose: In the recent years, social network has already stepped into the life of human, even becoming the indispensable part of modern life. However, what covers under the increasing social network is the more and more loneliness of people. And college students are in the early period of adulthood, which is the main period of avoiding loneliness, acquiring intimacy and experiencing the achievement of love. Aiming at students of Southwest Medical University, this research made a survey with the degree of dependence on loneliness and social network to understand the dependence degree current situation of the generation of youth to social network and the loneliness experience of college students as well as the existing relation between the two sides. In the hope for providing the reference for the mental health construction of later medical university. Methods: This paper used the quantitative research method to take a random sample with the 160 students of Southwest Medical University, and applied SPSS 17.0 to make the relevant statistical analysis. Results: There were 59.3\% of people fond of relay hot viewpoints or articles; and there were $65.3 \%$ of people thinking that it can thoroughly know someone that through his or her living situation on the network, for example, the recent life, diaries, pictures; and there were $45.3 \%$ of people saying that they usually chat with the friends of real life through the network; and there were $61.3 \%$ of interviewees showing that they will focus on one's social network dynamic owing to their love for someone or the better relationship with someone. Conclusions: 1. The degree of dependence on social network of university freshmen is usually not high. 2. The lower loneliness of college students, the more possibility of high degree of dependence on social network.
\end{abstract}

Keywords: College student, Loneliness, Social network.

\section{Introduction}

Along with the rapid development of modern information technology, network has played a more and more important role in people's life and made a great effect on the ideology and psychology of people. According to the statistical data of the statistical report of development situation of Chinese network annually published by Chinese Internet Information Center (CNNIC), it reveals that most of the internet population with all the occupations is college students, and the trend is increasing. In the latest statical report published in July, 2003, the statistical shows that the internet population has been about 68 million by the end of 20th, June, 2003. Among them, the proportion of people with the age from 18 to 35 is $66.6 \%$, and the proportion of people with the college degree or above is $55.2 \%$.

The main purpose of users surfing the internet is to acquire the information and entertainment. Internet has played a more and more important role in the real life, and the academic field has made more and more researches on the effect of internet use. The existing research has found that internet can have the effect on the cognition and thought, but the overuse of internet also may bring the negative or positive emotional experience to users. Stoll and Turkle found that some subjects have social isolation and social anxiety due to making friends through the network. And Kraut et al. found that the overuse of internet will lead to the increasing of loneliness and depression, specifically, their research founded that even though the internet is used because of the communication, the overuse of internet also result in the decreasing of social involvement and psychological well-being.

Loneliness is one kind of bad emotional experience and the depressed mood in the situation of not satisfied with the social interaction or interpersonal relationship for himself or herself. When something is wrong in the social interaction that is expected by one person, for example, intimacy, safety, the 
interpersonal relationship with mutual trust (includes friendship, affection and sexual love etc.), he or she will feel lone.

\section{Object and Method}

\subsection{Research object}

According to the questionnaire survey with students of this school in December, 2015, the research regarded the 160 students of Southwest Medical University as the object of survey with anonymous method of random sample, and the recovery was 100\%. Among them, the number of valid questionnaire is 149 , and the valid recovery is $91.3 \%$.

\subsection{Research method}

Based on the purpose of survey, the questionnaire made the change and compilation with the reference of College students network questionnaire and Loneliness scale, and its content includes the gender, major, grade, the understanding and dependence degree with network and the frequency degree of loneliness experience of subjects. And the questionnaire issuing, testing and recycling of students were done by the psychology teacher through formal training with the after-school time.

\subsection{Statistical handling}

By means of SPSS 17.0 to make the statistical analysis, $\mathrm{P}=-.068$

\section{Result}

\subsection{The current situation of college students social networking}

Table 3-1. I am fond of talking about my worldview, philosophy and dream on the network

\begin{tabular}{|c|c|c|c|c|c|}
\hline & Frequency & Percentage & $\begin{array}{c}\text { Valid } \\
\text { Percentage }\end{array}$ & $\begin{array}{c}\text { Cumulative } \\
\text { Percentage }\end{array}$ \\
\hline Valid & $\begin{array}{c}\text { Very } \\
\text { inconsistent }\end{array}$ & 17 & 11.3 & 11.4 & 11.4 \\
\hline & Inconsistent & 96 & 64.0 & 64.4 & 75.8 \\
\hline & Consistent & 36 & 24.0 & 24.2 & 100.0 \\
\hline & Total & 149 & 99.3 & 100.0 & \\
\hline Missing & Systematic & 1 & .7 & & \\
\hline \multicolumn{2}{r|}{} & 150 & 100.0 & & \\
\hline
\end{tabular}

Table 3-2. I think that the network dynamic of one person can make him or her be throughly understood

\begin{tabular}{|c|c|c|c|c|c|}
\hline & & Frequency & Percentage & Valid Percentage & $\begin{array}{c}\text { Cumulative } \\
\text { Percentage }\end{array}$ \\
\hline Valid & Very inconsistent & 17 & 11.3 & 11.4 & 11.4 \\
\hline & Inconsistent & 98 & 65.3 & 65.8 & 77.2 \\
\hline & Consistent & 31 & 20.7 & 20.8 & 98.0 \\
\hline & Well suited & 3 & 2.0 & 2.0 & 100.0 \\
\hline & Total & 149 & 99.3 & 100.0 & \\
\hline Missing & Systematic & 1 & .7 & & \\
\hline \multicolumn{2}{|r|}{ Total } & 150 & 100.0 & & \\
\hline
\end{tabular}


Table 3-3. I usually post one network dynamic when I feel rather happy or depressed

\begin{tabular}{|c|c|c|c|c|c|}
\hline & & Frequency & Percentage & Valid Percentage & Cumulative Percentage \\
\hline \multirow{2}{*}{ Valid } & Very inconsistent & 11 & 7.3 & 7.4 & 7.4 \\
\hline & Inconsistent & 54 & 36.0 & 36.2 & 43.6 \\
\hline & Consistent & 76 & 50.7 & 51.0 & 94.6 \\
\hline & Well suited & 8 & 5.3 & 5.4 & 100.0 \\
\hline & Total & 149 & 99.3 & .7 & \\
\hline Missing & Systematic & 1 & 100.0 & & \\
\hline
\end{tabular}

Table 3-4. The privacy authority is very low in my personal home page, and non-friends also can see my full information

\begin{tabular}{|c|c|c|c|c|c|}
\hline & & Frequency & Percentage & Valid Percentage & Cumulative Percentage \\
\hline \multirow{2}{*}{ Valid } & Very inconsistent & 23 & 15.3 & 15.4 & 15.4 \\
\hline & Inconsistent & 69 & 46.0 & 46.3 & 61.7 \\
\hline & Consistent & 51 & 34.0 & 34.2 & 96.0 \\
\hline & Well suited & 6 & 4.0 & 4.0 & 100.0 \\
\hline \multirow{2}{*}{ Missing } & Total & 149 & 99.3 & .7 & \\
\hline \multicolumn{2}{|c|}{ Systematic } & 1 & 100.0 & & \\
\hline
\end{tabular}

Table3-5 I like disclosing my affection condition on the social network

\begin{tabular}{|c|c|c|c|c|c|}
\hline & & Frequency & Percentage & Valid Percentage & Cumulative Percentage \\
\hline \multirow{2}{*}{ Valid } & Very inconsistent & 37 & 24.7 & 24.8 & 24.8 \\
\hline & Inconsistent & 101 & 67.3 & 67.8 & 92.6 \\
\hline & Consistent & 11 & 7.3 & 7.4 & 100.0 \\
\hline Missing & Total & 149 & 99.3 & 100.0 & \\
\hline \multicolumn{2}{|c|}{ Systematic } & 1 & 100.0 & & \\
\hline
\end{tabular}

Table 3-6. I think that those people known from the social network are not friends, because there is no so-called friendship

\begin{tabular}{|c|c|c|c|c|c|}
\hline & & Frequency & Percentage & Valid Percentage & $\begin{array}{l}\text { Cumulative } \\
\text { Percentage }\end{array}$ \\
\hline \multirow[t]{5}{*}{ Valid } & Very inconsistent & 3 & 2.0 & 2.0 & 2.0 \\
\hline & Inconsistent & 27 & 18.0 & 18.1 & 20.1 \\
\hline & Consistent & 108 & 72.0 & 72.5 & 92.6 \\
\hline & Well suited & 11 & 7.3 & 7.4 & 100.0 \\
\hline & Total & 149 & 99.3 & 100.0 & \\
\hline Missing & Systematic & 1 & .7 & & \\
\hline \multicolumn{2}{|c|}{ Total } & 150 & 100.0 & & \\
\hline
\end{tabular}


Table 3-7. When I want to know someone, I will go to see his behavior on the social network

\begin{tabular}{|c|c|c|c|c|c|}
\hline & & Frequency & Percentage & Valid Percentage & $\begin{array}{c}\text { Cumulative } \\
\text { Percentage }\end{array}$ \\
\hline Valid & Very inconsistent & 2 & 1.3 & 1.3 & 1.3 \\
\hline & Inconsistent & 42 & 28.0 & 28.2 & 29.5 \\
\hline & Consistent & 101 & 67.3 & 2.7 & 97.3 \\
\hline & Well suited & 4 & 2.7 & 100.0 & 100.0 \\
\hline Missing & Total & 149 & 99.3 & & \\
\hline
\end{tabular}

Table 1-1 shows that there are $24.2 \%$ interviewees expressing that they like talking about my worldview, philosophy and dream on the network; Table 1-2 shows that there are $20.8 \%$ interviewees expressing their approval that the network dynamic of one person can make him or her be throughly understood; Table 1-7 also shows that there are $70 \%$ college students will choose the behavior on the social network to know one person. Table 1-3 shows that there are 51.0\% interviewees expressing that they usually post one living dynamic when they feel rather happy or depressed. Table 1-4 shows that there are $46 \%$ college students have the higher privacy authority, while $34 \%$ college students have the lower privacy authority. Table 1-5 shows that there are $24.7 \%$ college students who are very unwilling to disclose their own affection condition on the social network, while $67.3 \%$ college students unwilling to do that; Table 1-6 shows that there are $72.0 \%$ college students thinking that those people known from the social network are not friends.

\subsection{The current situation of college students' loneliness}

Table 3-8. Do you often feel that someone truly understand you?

\begin{tabular}{|c|c|c|c|c|c|}
\hline & & Frequency & Percentage & Valid Percentage & $\begin{array}{c}\text { Cumulative } \\
\text { Percentage }\end{array}$ \\
\hline Valid & Never & 10 & 6.7 & 6.7 & 6.7 \\
\hline & Rarely & 61 & 40.7 & 40.9 & 47.7 \\
\hline & Sometimes & 67 & 44.7 & 45.0 & 100.0 \\
\hline & Always & Total & 11 & 7.3 & 100.0 \\
\hline Missing & Systematic & 1 & 99.3 & & \\
\hline
\end{tabular}

As can be seen from the table 2-1, there are $40.7 \%$ interviewees thinking that they rarely feel that someone truly knows them, and there are $44.7 \%$ interviewees thinking that they sometimes feel that someone truly understands them.

\subsection{The relevant relationship of college students' loneliness with the degree of dependence on social network}

Based on the correlation analysis of SPSS 17.0, the relevant degree of college students' loneliness with the degree of dependence on social network $\mathrm{P}=-0.68$.

\section{Discussion}

This research found that most college students think that network situation (diaries, pictures, relay, etc.) can well reflect the characteristics and viewpoints of one person. When one person wants to know an unfamiliar person, most people will scan the zone or circle of friends of this person. Psychologist Ericson pointed out that those people aging from 18 to 25 are in the early period of adulthood whose 
development task is avoiding loneliness, acquiring intimacy and achievement of experiencing love. College students in this stage long to contact and know the opposite sex. When they have the good opinion with one opposite sex, it will usually make them feel embarrassed if they directly ask friends, and network dynamics often becomes their first choice at this time. Meanwhile, social network also provides a very good communication platform for those college students having little contact with the opposite sex.

In addition, part of college students are unwilling to disclose their own too much information on social network, so they usually have the higher zone authority. There are varieties of reasons. Maybe they are worry about the disclosing of personal information, also maybe they are in order to prevent the bothering by strangers. And also some students hold the indifferent attitude. Most college students hold the mistrustful attitude with making friends through internet, because they think that true friends cannot be made by means of social network; and this usually is due to the heavy study task of medical college students who have little time to make friends on the network; in addition, the social network is rather elusive, as a result, the sense of trust among people is rather low.

This research found that the score of UCLA has a negative correlation with the dependence on social network, namely that those people who have lower loneliness in the real life prefer to share their own emotions, philosophy, worldview and dream on internet. This is inconsistent with the research result of Jiayan Liu et al. but consistent with the research of Shaw et al. They think that loners can make use of network to construct good support system so that they can lower their loneliness. And most of the objects that college students chat with are familiar people in the real life, so familiar people in two different places can close with each other because of one message under the context of familiar environment. Under this circumstance, social network indeed has certain effect on the lowering of loneliness. At the same time, it can make some introvert students talk more confidently on such a platform that eliminates part mental disorder, so they can be not afraid of losing face and avoid embarrassment.

\section{The Necessary Improvement Aspects of This Research}

Due to the first time to leave home with long time and far distance, freshmen may confuse situational loneliness of short term and quality loneliness of long term. Therefore, it will have an effect with certain degree on the test result of loneliness that choosing the freshman to survey.

The design of questionnaire. The first one is the design insufficiency of population variable, only including the three of grade, major and gender. The second one is that quantitative questions are not been designed, for example, the frequency of internet and online time every time. And it didn't include the question that directly inquire the relationship between two sides.

The design of questionnaire. The first one is the design insufficiency of population variable, only including the three of grade, major and gender. The second one is that quantitative questions are not been designed, for example, the frequency of internet and online time every time. And it didn't include the question that directly inquire the relationship between two sides, for example, I always feel more lone every time after I chat online. The third one is that it should design such a question at the end of the questionnaire, Please choose the attitude when you fill out the questionnaire: 1 . Very careful 2. No interest or short time, answer in random. The fourth one is that the number of question is also a bit more, and they still need to be carefully filtered to avoid the repeat of the same questions. Aiming at the above suggestions, this questionnaire can be made certain adjustment later.

\section{Acknowledgements}

Fund Project: The key project of the ideological and political education research center of Sichuan province "The existence and development of human beings--study of the ideological dimension of the ideological and political education of college students" (No. CSZ14001); Sichuan Applied Psychology Research Center: Study on the brain function of college students with depression under resting state: differentiation or integration? (No.CSXL-152218) 


\section{References}

[1]. Chinese Internet Information Center (CNNIC). The 12th statistical report of development condition of Chinese internet. http://www.cnnic.cn/develst/2003-7/,2003-11-27

[2]. Morahan-Martin J,Schumacher P. Incidence and correlates of pathological internet use among college student, Computer in Human Behavior,2000,16:13-29

[3]. Kraut R,Patterson M,Lundmark V,Kielser S,et al.Internet paradox:A social technology that reduces social and involvement and psychological well-being? American Psychologist,1998, 9:1017--1031

[4]. Sproull L,Faraj S.Atheism sex and database:the net as a social technology. In: Kahin B,Keller J.Public access to the internet Cambridge, MA: MIT Press,1995.62-81

[5]. Stoll C.Silicon Snake Oil.NEW YORK:Doubleday,1995

[6]. Turkle S.Virtuality and its discontents: Searching for community in cyberspace. The American Prospect, 1996,24:50-57

[7]. Ping Liu. The assessment of loneliness. Edited by Xiangdong Wang. Mental health assessment scale manual, Chinese mental health magazine, 1999 supplementary issue: 282-289

[8]. Jiayan Liu. The research of relation of college students loneliness and network use characteristic. Chinese clinical psychology magazine, 2004, 12,3 :286-287

[9]. Shaw H,Grant M. In defense of the internet: The relationship between internet communication and depression, loneliness, self-Esteem, and perceived social support. CyberPsychology \& Behavior ,2002,5(2):157-171 